\title{
Effect of Two Different Priming Doses of Cisatracurium in Addition to its Bolus Dose- A Randomised Double-Blind Controlled Trial
}

\author{
Sandip Sinha1, Tirtha Ratan Ghosh², Moumita Saha3 , Arpan Roy, Diptimay Majumder5, Sruthi Naresh6, \\ Nazia Tarannum 7 , Dona Kirtania ${ }^{8}$
}

\begin{abstract}
${ }^{1}$ Department of Anaesthesiology, Bankura Sammilani Medical College and Hospital, Bankura, West Bengal, India. ${ }^{2}$ Department of Anaesthesiology, Bankura Sammilani Medical College and Hospital, Bankura, West Bengal, India. ${ }^{3}$ Department of Anaesthesiology, Bankura Sammilani Medical College and Hospital, Bankura, West Bengal, India. ${ }^{4}$ Department of Anaesthesiology, Bankura Sammilani Medical College and Hospital, Bankura, West Bengal, India. ${ }^{5}$ Department of Anaesthesiology, Bankura Sammilani Medical College and Hospital, Bankura, West Bengal, India. ${ }^{6}$ Department of Anaesthesiology, Bankura Sammilani Medical College and Hospital, Bankura, West Bengal, India. ${ }^{7}$ Department of Anaesthesiology, Bankura Sammilani Medical College and Hospital, Bankura, West Bengal, India. ${ }^{8}$ Department of Anaesthesiology, Bankura Sammilani Medical College and Hospital, Bankura, West Bengal, India.
\end{abstract}

\section{ABSTRACT}

\section{BACKGROUND}

Nondepolarizing muscle relaxants (NDMRs) used in current clinical practice have slower onset of action and are not suitable for rapid control of airway. In order to reduce interval between the administration of NDMRs to optimal intubating conditions, administering priming dose, a sub-paralysing dose of the NDMRs, few minutes before giving a large calculated dose is recommended for smooth tracheal intubation. Cisatracurium Besylate, an agent with 4 times potency of Atracurium, has a longer onset time. We wanted to compare two different priming doses of Cisatracurium with a bolus administration to arrive at an optimal priming dose of Cisatracurium.

\section{METHODS}

In this prospective randomised double-blind study, we evaluated the effect of two different priming regimens (10 and 15 microgram $/ \mathrm{Kg}$ ) from the total $100 \mathrm{mcg} / \mathrm{Kg}$ of Cisatracurium with regard to onset time of intubation as assessed by TOF (Train of Four) disappearance time compared to a bolus administration. 90 patients scheduled for various elective abdominal surgeries under general anaesthesia with endotracheal intubation, were enrolled and were divided into 2 study groups and 1 control group. Systolic and diastolic blood pressures, mean arterial pressure, heart rate, oxygen saturation and capnography were assessed before administration of study drug, before intubation, and subsequently, immediately after intubation and at 1,3 and 10 minutes after intubation. Also, TOF disappearance time by acceleromyograph, intubation score by Viby Mogensen and adverse effects related to priming were assessed.

\section{RESULTS}

TOF disappearance time was shorter $(148.07 \pm 12.63$ second $)$ in the group with priming dose of $15 \mathrm{mcg} / \mathrm{Kg}$ Cisatracurium than in the group with priming dose of 10 $\mathrm{mcg} / \mathrm{Kg}(177.13 \pm 9.54)$. TOF disappearance time was longer $(211.70 \pm 25.97)$ in the group where no priming drug but only the bolus dose was used for intubation. There were no statistically significant differences in intubation scores, haemodynamic parameters among all three groups in all time intervals. No adverse effects were found in any groups.

\section{CONCLUSIONS}

Priming dose of Cisatracurium reduces the onset time for intubation without affecting intubating conditions and haemodynamic parameters. Reduction in the onset time for intubation is more with higher priming doses $(15 \%)$ than with lower priming dose (10\%).

\section{KEY WORDS}

Cisatracurium, Priming Dose, Onset Time
Corresponding Author: Dr. Tirtha Ratan Ghosh, Flat No. B 2/12, Shilpakanan Phase 3, Bidhannagar, Durgapur, Dist., Pashchim Bardhaman, West Bengal, India.

E-mail: dr.tirthaghosh@gmail.com

DOI: $10.14260 /$ jemds/2019/748

Financial or Other Competing Interests: None.

How to Cite This Article:

Sinha S, Ghosh TR, Saha M, et al. Effect of two different priming doses of cisatracurium in addition to its bolus dosea randomised double blind controlled trial. J. Evolution Med. Dent. Sci. 2019;8(46): 3454-3458, DOI: 10.14260/jemds/2019/748

Submission 21-09-2019, Peer Review 28-10-2019, Acceptance 05-11-2019, Published 18-11-2019. 


\section{BACKGROUND}

Succinylcholine is currently used to facilitate rapid intubation of trachea during anaesthesia, but in instances when succinylcholine has been contraindicated or undesirable, use of large doses of non-depolarising neuromuscular blocking drugs (NDMRs) has been suggested to achieve intubating condition rapidly. The NDMRs used in current clinical practice have slower onset of action and are not suitable for rapid control of airway. In order to reduce interval between the administration of NDMRs to optimal intubating conditions, administering priming dose, a sub-paralysing dose of the NDMRs, few minutes before giving a large calculated dose is recommended for smooth tracheal intubation. studies ${ }^{1-5}$ have demonstrated the ability of priming technique to decrease the onset time of neuromuscular blockade at the adductor pollicis muscle. It is expected that the priming interval should be adjusted so that the maximal effect of priming dose coincides with the time of intubation. Most studies have found that time duration between priming dose and intubation dose is $4 \mathrm{~min}$ at least as good if not better than other interval tested.5-7 The time to maximal blockade may be different in peripheral and respiratory muscles, probably because of differences in blood flow. Thus, the observation of intubating conditions constitutes a more clinically relevant endpoint than the measurement of adductor pollicis response. Larger doses are more effective in accelerating the onset of blockade, ${ }^{5-8}$ but they may be associated with more adverse effects. Cisatracurium Besylate a stereoisomer of Atracurium is a nondepolarising Benzylisoquinolinium, intermediate acting, neuromuscular blocking agent with 4 times potency of Atracurium. ${ }^{9}$ Compared to Atracurium, Cisatracurium produces less laudanosine and releases less histamine, but it has a longer onset time. Objective of this prospective randomised double-blind study is to evaluate the effect of two different priming regimens on the onset time (TOF disappearance time) of $100 \mathrm{mcg} / \mathrm{Kg}$ of Cisatracurium when compared to a bolus administration.

\section{METHODS}

This prospective randomised double-blind study was conducted after obtaining permission from Institutional Ethics Committee among 90 randomly selected patients undergoing various elective abdominal surgeries under general anaesthesia. Sample size of was obtained using the formula: Sample size $=\left[\left(\mathrm{Z}_{\alpha}+\mathrm{Z}_{\beta}\right)^{2} \times 2 \times \mathrm{S}^{2}\right] / \mathrm{d}^{2}$, where $\mathrm{SD}=$ Standard deviation, $Z_{\alpha}=\alpha$ error $=1.96, Z_{\beta}=\beta$ error $=0.84, d=$ mean difference. Twenty second was considered as significant reduction of onset time so mean difference (d) was 20. From the study Of Duggappa et al we found SD in control group was 22.96. So using all these values we got sample size 21 for each group and increased to 30 for any possible loss during study. So the final size of sample was 90. Written informed consent was obtained from the willing participants. Inclusion criteria comprised patients of American Society of Anesthesiologists physical status I and II, of either sex, aged between 18 to 60 years. Exclusion criteria were predicted difficult airway, abuse of narcotics, alcohol or drug, regular intake of beta-blockers, anxiolytics, antidepressant, anticonvulsant, antipsychotic drugs, drug allergy to Cisatracurium, ischaemic heart disease, renal and hepatic dysfunction, hypertension, diabetes mellitus, pheochromocytoma. A total of 90 patients were allocated into 3 groups by computer generated random number table. Group A (Control Group) received no priming dose, but normal saline to avoid bias. Group B received Inj. Cisatracurium $10 \mathrm{mcg} / \mathrm{Kg} \&$ Group-C received Inj. Cisatracurium $15 \mathrm{mcg} / \mathrm{Kg}$ as priming doses respectively. After 4 mins Group A received Inj. Cisatracurium 100 $\mathrm{mcg} / \mathrm{Kg}$, whereas Group-B and Group C received $90 \mathrm{mcg} / \mathrm{Kg}$ and $85 \mathrm{mcg} / \mathrm{Kg}$ Inj. Cisatracurium respectively, as intubation doses.

On the day before surgery, each patient was attended and examined properly for a preoperative counselling and repeat anaesthetic check-up. On arrival in the operation room multichannel monitor was applied. $\mathrm{SpO}_{2}$, ECG and heart rate were monitored continuously, and non-invasive recordings of systolic, diastolic and mean arterial pressure were taken. An IV line was started with Ringer's Lactate after putting an 18G intravenous cannula. Acceleromyograph was attached to the dominant hand of the patient to visually monitor thumb adduction by stimulating ulnar nerve at wrist. Patients were preoxygenated using $100 \%$ oxygen through a tight-fitting facemask for $3 \mathrm{~min}$, then they were pre-medicated with Inj. Glycopyrrolate $4 \mathrm{mcg} / \mathrm{Kg}$; Inj. Midazolam $0.025 \mathrm{mg} / \mathrm{Kg}$ intravenously. Before giving induction agent, control group $\mathrm{A}$ received normal saline, Group B and Group-C received priming doses of Inj. Cisatracurium. Oxygen administration continued for the next $4 \mathrm{~min}$, during which adverse effects related to priming were observed and recorded. After completion of $4 \mathrm{~min}$ after priming, intravenous induction of the anaesthesia was done by using Inj. Propofol $2 \mathrm{mg} / \mathrm{Kg}$, Inj. Fentanyl $2 \mu \mathrm{g} / \mathrm{Kg}$. Then intubating dose of Inj. Cisatracurium was administered which was $100 \mathrm{mcg} / \mathrm{Kg}$ in Group A, 90 $\mathrm{mcg} / \mathrm{Kg}$ in Group B, and $85 \mathrm{mcg} / \mathrm{Kg}$ in Group C, respectively, thus ensuring that the total dose of Inj. Cisatracurium used was $100 \mathrm{mcg} / \mathrm{Kg}$ body weight. After completion of administration of intubating dose of Inj. Cisatracurium, the peripheral nerve stimulator (placed to stimulate ulnar nerve of dominant hand at wrist using $40 \mathrm{~mA}$ current strength) was switched on to monitor the TOF count by visual means of thumb adduction and also started the timer to record the time from the administration of intubating dose of Inj. Cisatracurium till TOF count reached zero. The TOF disappearance time was recorded. Once the patient became apnoeic, bag mask ventilation was performed with Oxygen and Isoflurane. Isoflurane was adjusted to achieve a minimum alveolar concentration of 1-1.3. After TOF count reached zero, intubation was carried out and surgical procedure began. Systolic and diastolic blood pressures and mean arterial pressure, heart rate, oxygen saturation and capnography were assessed and recorded before administration of study drug, before intubation, and subsequently, immediately after intubation and at 1, 3 and 10 minutes after intubation. Muscle relaxation was maintained by inj Cisatracurium $0.03 \mathrm{mg} / \mathrm{kg}$ as top up doses. The neuromuscular monitoring was done using a Acceleromyograph (TOF-Watch® SX, Organon (Ireland) Ltd.). After completion of surgery, reversal was achieved with Inj. 
Neostigmine $0.05 \mathrm{mg} / \mathrm{Kg} \& \mathrm{Inj}$. Glycopyrrolate $0.01 \mathrm{mg} / \mathrm{Kg}$. After adequate reversal, patient was shifted to PACU.

\section{Statistical Analysis}

Statistical analysis was done using SPSS (version 24.0; SPSS Inc., Chicago, IL, USA) and Graph Pad Prism version 5. Oneway ANOVA test was used to compare means of three or more samples for numerical data (using the $\mathrm{F}$ distribution). For significance testing, $\chi 2$ test, Student's t-test or analysis of variance was performed as appropriate. P-value $\leq 0.05$ was considered statistically significant.

\section{RESULTS}

Age, weight, height, BMI, duration of surgery, male - female distribution and ASA status of the patients in three groups were comparable (Table 1). SBP, DBP and MBP were comparable in three groups just before administration of the study drug and it remained comparable just before intubation, immediately after intubation 1,3 and 10 minutes after intubation (Table 2). Heart rates just before drug administration in all groups were comparable. It was higher just after intubation and gradually reduced over time, but all three groups followed the same trend and values remained comparable at all time frames (just before intubation, immediately after intubation, 1,3 and $10 \mathrm{~min}$ after intubation) (Table 3). $\mathrm{SpO}_{2}$ was 100 percent in all three groups at all time frames (Table 3).

\begin{tabular}{|c|c|c|c|c|}
\hline Parameter & $\begin{array}{c}\text { Group A } \\
(\mathbf{n = 3 0})\end{array}$ & $\begin{array}{c}\text { Group B } \\
\text { (n= 30) }\end{array}$ & $\begin{array}{c}\text { Group C } \\
\text { (n= 30) }\end{array}$ & p \\
\hline Age(yrs.) (Mean \pm SD) & $33.77 \pm 10.18$ & $33.40 \pm 8.19$ & $33.57 \pm 11.44$ & 0.99 \\
\hline Weight (Kg) (Mean \pm SD) & $56.26 \pm 5.69$ & $55.27 \pm 5.22$ & $55.10 \pm 6.11$ & 0.69 \\
\hline Height (cm) (Mean \pm SD) & $161.63 \pm 7.84$ & $163.97 \pm 9.52$ & $164.60 \pm 8.99$ & 0.39 \\
\hline BMI (Kg/ m² (Mean \pm SD) & $21.62 \pm 2.44$ & $20.73 \pm 2.94$ & $20.54 \pm 3.45$ & 0.32 \\
\hline OT duration (Min) (Mean \pm SD) & $88.83 \pm 9.49$ & $90.80 \pm 6.29$ & $90.70 \pm 5.01$ & 0.49 \\
\hline Male: Female Patients & $20: 10$ & $18: 12$ & $17: 13$ & 0.72 \\
\hline ASA I:ASAII Patients & $22: 8$ & $19: 11$ & $22: 8$ & 0.62 \\
\hline \multicolumn{6}{|c|}{ Table 1. Demographic Parameters and Duration of } \\
\hline nery in 3 Groups \\
\hline
\end{tabular}

\begin{tabular}{|c|c|c|c|c|}
\hline Parameter & $\begin{array}{c}\text { Group A } \\
(n=30) \\
(\text { Mean } \pm \text { SD) }\end{array}$ & $\begin{array}{c}\text { Group B } \\
(\mathrm{n}=30) \\
(\text { Mean } \pm \text { SD })\end{array}$ & $\begin{array}{c}\text { Group C } \\
(\mathrm{n}=30) \\
(\text { Mean } \pm S D)\end{array}$ & $\mathbf{p}$ \\
\hline SBP before administration of drug & $121.60 \pm 6.35$ & $122.00 \pm 9.96$ & $123.13 \pm 9.38$ & 0.78 \\
\hline SBP before intubation & $110.07 \pm 6.09$ & $109.93 \pm 8.65$ & $110.27 \pm 8.11$ & 0.98 \\
\hline SBP immediately after intubation & $118.27 \pm 7.59$ & $116.13 \pm 8.66$ & $113.80 \pm 4.60$ & 0.08 \\
\hline SBP at $1 \mathrm{~min}$ & $113.60 \pm 7.07$ & $117.67 \pm 6.39$ & $116.60 \pm 8.24$ & 0.08 \\
\hline SBP at $3 \mathrm{~min}$ & $111.13 \pm 6.53$ & $112.86 \pm 5.69$ & $110.66 \pm 7.50$ & 0.40 \\
\hline $\mathrm{SBP}$ at $10 \mathrm{~min}$ & $111.26 \pm 5.52$ & $113.60 \pm 6.77$ & $110.67 \pm 6.11$ & 0.15 \\
\hline DBP before administration of drug & $80.73 \pm 4.22$ & $82.00 \pm 5.41$ & $80.87 \pm 4.95$ & 0.54 \\
\hline DBP before intubation & $74.53 \pm 4.58$ & $76.60 \pm 5.36$ & $74.13 \pm 4.23$ & 0.10 \\
\hline DBP immediately after intubation & $80.53 \pm 5.50$ & $80.33 \pm 4.61$ & $79.60 \pm 6.27$ & 0.78 \\
\hline DBP at 1 Min & $78.27 \pm 5.27$ & $79.47 \pm 5.48$ & $78.80 \pm 4.22$ & 0.65 \\
\hline DBP at 3 Min & $73.93 \pm 5.47$ & $75.20 \pm 4.66$ & $75.40 \pm 4.17$ & 0.47 \\
\hline \begin{tabular}{|l|} 
DBP at $10 \mathrm{Min}$ \\
\end{tabular} & $72.67 \pm 5.88$ & $74.80 \pm 4.57$ & $73.73 \pm 3.88$ & 0.24 \\
\hline MBP before administration of drug & $97.51 \pm 3.94$ & $95.33 \pm 5.20$ & $94.95 \pm 4.64$ & 0.07 \\
\hline MBP before intubation & $86.40 \pm 3.84$ & $87.71 \pm 4.98$ & $86.18 \pm 3.72$ & 0.31 \\
\hline MBP immediately after intubation & $93.11 \pm 4.49$ & $92.27 \pm 4.78$ & $91.00 \pm 4.0$ & 0.18 \\
\hline \begin{tabular}{|c|} 
MBP at 1 Min \\
\end{tabular} & $90.04 \pm 4.31$ & $92.0 \pm 4.00$ & $91.40 \pm 3.36$ & 0.14 \\
\hline MBP at 3 Min & $86.00 \pm 4.00$ & $88.00 \pm 4.00$ & $87.15 \pm 3.22$ & 0.12 \\
\hline MBP at 10 Min & $86.00 \pm 4.00$ & $88.00 \pm 4.00$ & $86.04 \pm 2.97$ & 0.06 \\
\hline \multicolumn{5}{|c|}{ Table 2. SBP, DBP and MAP in 3 Groups } \\
\hline & & & & \\
\hline
\end{tabular}

\begin{tabular}{|c|c|c|c|c|}
\hline Parameter & $\begin{array}{c}\text { Group A } \\
(\mathrm{n}=30) \\
(\text { Mean } \pm \text { SD })\end{array}$ & $\begin{array}{c}\text { Group B } \\
(n=30) \\
(\text { Mean } \pm \text { SD })\end{array}$ & $\begin{array}{c}\begin{array}{c}\text { Group C } \\
(n=30) \\
(M e a n \pm S D)\end{array} \\
\end{array}$ & $\mathbf{p}$ \\
\hline HR before administration of drug & $79.63 \pm 6.48$ & $81.37 \pm 5.66$ & $81.17 \pm 5.40$ & 0.46 \\
\hline HR before intubation & $74.70 \pm 5.64$ & $75.93 \pm 5.72$ & $77.90 \pm 5.42$ & 0.09 \\
\hline HR immediately after intubation & $88.00 \pm 6.12$ & $86.07 \pm 5.67$ & $85.07 \pm 6.59$ & 0.18 \\
\hline HR at $1 \mathrm{~min}$ & $82.43 \pm 5.92$ & $84.93 \pm 4.13$ & $83.13 \pm 5.23$ & 0.16 \\
\hline HR at & $85.36 \pm$ & $84.93 \pm 4.13$ & 5.23 & 0.16 \\
\hline HR at & & $79.73 \pm 3.65$ & 4.30 & 0.14 \\
\hline $\mathrm{SpO}_{2}$ before & & & & NA \\
\hline $\mathrm{SpO}_{2}$ befo & & & & NA \\
\hline $\mathrm{SpO}_{2}$ immediate after intubation & & & 0.00 & NA \\
\hline $\mathrm{SpO}_{2}$ at $1 \mathrm{~min}$ & & & $100 \pm 0.00$ & NA \\
\hline $\mathrm{SpO}_{2}$ & 100 & $100 \pm 0$ & $100 \pm 0.00$ & NA \\
\hline $\mathrm{SpO}_{2} \mathrm{a}$ & & & $100 \pm 0.00$ & NA \\
\hline $\mathrm{EtCO}_{2}$ before administration of drug & $33.37 \pm 2.22$ & $33.53 \pm 2.06$ & $33.50 \pm 2.01$ & 0.95 \\
\hline $\mathrm{EtCO}_{2}$ before intubation & $32.73 \pm 2.65$ & $33.10 \pm 2.12$ & $32.73 \pm 2.13$ & 0.78 \\
\hline $\mathrm{EtCO}_{2}$ immediate after intubation & $33.83 \pm 1.67$ & $34.40 \pm 1.59$ & $33.87 \pm 1.74$ & 0.34 \\
\hline $\mathrm{EtCO}_{2}$ at $1 \mathrm{~min}$ & $33.93 \pm 1.53$ & $34.43 \pm 1.45$ & $34.47 \pm 1.52$ & 0.32 \\
\hline $\mathrm{EtCO}_{2}$ at $3 \mathrm{~min}$ & $34.17 \pm 1.58$ & $33.97 \pm 1.79$ & $34.13 \pm 1.31$ & 0.87 \\
\hline $\mathrm{EtCO}_{2}$ at $10 \mathrm{~min}$ & $34.57 \pm 1.36$ & $34.03 \pm 2.01$ & $34.07 \pm 1.78$ & 0.41 \\
\hline \multicolumn{5}{|c|}{ Table 3. Heart Rate, $\mathrm{SpO}_{2}$ and EtCO $\mathrm{C}_{2}$ in 3 Groups } \\
\hline & & & & \\
\hline
\end{tabular}

\begin{tabular}{|c|c|c|c|c|}
\hline Intubation Score & Group-A & Group-B & Group-C & p Value \\
\hline Excellent & 26 & 29 & 30 & \multirow{2}{*}{0.06} \\
\hline Good & 4 & 1 & 0 & \\
\hline Fair & 0 & 0 & 0 & \\
\hline Poor & 0 & 0 & 0 & \\
\hline \multicolumn{4}{|c|}{ Table 4. Intubation Score in the 3 Groups } \\
\cline { 1 - 1 } n=Number of patients in each group, p<0.05 was considered significant. \\
\hline
\end{tabular}

\begin{tabular}{|c|c|c|c|}
\hline & & Mean \pm SD & p \\
\hline \multirow{2}{*}{$\begin{array}{c}\text { TOF disappearance } \\
\text { time(sec) }\end{array}$} & Group- $\mathrm{A}(\mathrm{n}=30)$ & $211.70 \pm 25.97$ & \multirow{2}{*}{$<0.00$} \\
\cline { 2 - 3 } & Group-B $(\mathrm{n}=30)$ & $177.13 \pm 9.54$ & $148.07 \pm 12.63$ \\
\cline { 2 - 3 } & Group-C(n=30) & \\
\hline \multicolumn{2}{|c|}{ Table 5. TOF Disappearance Time in the 3 Groups } \\
\hline n=Number of patients in each group, $\mathrm{p}<0.05$ was considered significant. \\
\hline
\end{tabular}

Difference in $\mathrm{EtCO}_{2}$ in between groups were not statistically significant (Table 3). In Group-A, 26 (86.7\%) patients had excellent intubation scores and $4(13.33 \%)$ patients had good intubation scores. In Group-B, 29(96.7\%) patients had excellent intubation scores and 1 (3.3\%) patients had good intubation score. In Group-C, 30 (100\%) patients had excellent intubation scores. There was no patient with fair or poor intubation scores in all three groups. There was no statistically significant differences in intubation scores among different groups $(\mathrm{p}=0.0637)$ (Table 4). Mean TOF disappearance time (Onset time of intubating dose) in Group A was $211.70 \pm 25.97$ seconds. In Group-B, the mean TOF disappearance time was $177.13 \pm 9.54$ seconds. In GroupC, the mean TOF disappearance time was $148.07 \pm 12.63$ seconds. These difference in TOF disappearance time among three groups were statistically highly significant $(p<0.00)$.

\section{DISCUSSION}

The introduction of neuromuscular blockers revolutionized the anaesthetic practice. Suxamethonium is the only depolarizer in use which causes profound muscle relaxation within 60 seconds after intravenous administration and it remains the drug of choice when rapid tracheal intubation is needed. However, there are certain clinical situations where Suxamethonium is contraindicated. ${ }^{10}$ Most of the NDMRs have slower onset of action and are not suitable for rapid control of airway. Various techniques have been studied to decrease the onset time of various NDMRs. Some of them are - priming principle, timing principle, administering large doses, and combining different neuromuscular blocking 
agents. The studies conducted by Gergis et al. and Hutton et al. ${ }^{11}$ Reported that the onset of neuromuscular block could be hastened by administering small dose before the intubating dose. The term priming dose was coined by Foldes. ${ }^{12}$ After that, several studies were conducted based on the priming principle. With the use of rocuronium this method is somewhat forgotten, although still used. In this method a small, subparalyzing dose of the nondepolarizing agent $(20 \%$ of the ED95 or $10 \%$ of the intubating dose) is administered to the patient 2-4 min before the intubating dose of the drug. The mechanism is that when priming dose is administered, it will accelerate the onset of neuromuscular blockade by $30-$ 60 seconds, thereby facilitating intubation quickly within 90 seconds after the intubating dose. ${ }^{13}$ Priming dose results in $70 \%-75 \%$ of cholinergic receptor occupancy and subsequent dose administered after the priming dose leads to $>90 \%$ receptor occupancy, which is required for profound muscle relaxation. In reality, intubating conditions after priming do not match those after suxamethonium. Some adverse effects were also encountered while priming had been employed and these are patient discomfort, aspiration risks, difficulty in swallowing/coughing and diploplia. ${ }^{13,14}$ This technique is not applicable for those with difficult airway and increased sensitivity to neuromuscular blocking drugs such as myasthenia gravis or those who are on drugs known to interfere with neuromuscular function.

Cisatracurium is an NDMR having potency almost 4 times more than Atracurium. It does not cause histamine release and is cardiostable. It is metabolized by Hoffmann elimination so can be used in patients with decreased hepatic or renal function. The problem with this NDMR is the delayed onset of action (2-3 minutes). ${ }^{15}$ Very few studies were conducted regarding priming dose of Cisatracurium.

Thus, the present study was designed to study the effects of two different priming regimen on the onset time of 100 $\mathrm{mcg} / \mathrm{Kg}$ of Cisatracurium when compared to a bolus administration. In this study 90 patients were selected after thorough pre-anaesthetic assessment and investigations and were randomly divided into 3 groups (Group A, Group B, \& Group C) with 30 cases in each group. Group A received 100 $\mathrm{mcg} / \mathrm{Kg}$ Cisatracurium as bolus without any priming dose. Group B received injection Cisatracurium $10 \mathrm{mcg} / \mathrm{Kg}$ \& Group-C received $15 \mathrm{mcg} / \mathrm{Kg}$ as priming dose and after 4 minutes, $90 \mathrm{mcg} / \mathrm{Kg} \& 85 \mathrm{mcg} / \mathrm{Kg}$ as intubation doses respectively.

In the present study onset time of the intubating dose of Cisatracurium, measured by TOF disappearance time, was lowest in Group C $(148.07 \pm 12.63$ seconds) where higher fraction of Cisatracurium (15\% of total dose) was used. It was higher in Group B (177.13 \pm 9.54 seconds) where only $10 \%$ of total dose was used as priming dose but it was lower than Group A (211.70 \pm 25.97 seconds) where no priming dose was used. The difference of TOF disappearance times were statistically highly significant.

Schmidt J et al., compared a bolus application and a priming technique with respect to the laryngeal onset time and peak effect. Onset time of relaxant at the laryngeal muscles was significantly shorter in the high dose priming group (Priming dose of $0.015 \mathrm{mg} / \mathrm{Kgbw} 3$ minutes before $0.085 \mathrm{mg} / \mathrm{Kgbw}$ of Cisatracurium) ( $80 \pm 17 \mathrm{~s})$, when compared to the low dose priming group (priming dose of 0.01 $\mathrm{mg} /$ Kgbw 3 minutes before $0.09 \mathrm{mg} / \mathrm{Kgbw}$ of Cisatracurium)
$(128 \pm 23 \mathrm{~s})$ and bolus group (142 $\pm 29 \mathrm{~s})$. Onset time at the adductor pollicis muscle (APM) was also significantly shorter in the high dose priming group (154+/-35 s), when compared with the bolus group $(226+/-76$ s). The recovery of the neuromuscular function measured at the APM showed no differences between the groups. ${ }^{16}$ Findings of this study corroborates our study regarding the onset time of Cisatracurium and the effect of different priming doses.

Duggappa et al. did a prospective randomized controlled study where total dose of Atracurium used in all patients was $0.5 \mathrm{mg} / \mathrm{Kg}$ body weight, including the priming dose. Each group received different priming doses of Atracurium as follows: Group A received $0.05 \mathrm{mg} / \mathrm{Kg}$ body weight, Group B received $0.025 \mathrm{mg} / \mathrm{Kg}$ body weight, whereas Group $\mathrm{C}$ (control) received saline as priming dose. They found that time required for TOF count to reach zero was approximately 147s while using $0.05 \mathrm{mg} / \mathrm{Kg}$ body weight and $193 \mathrm{~s}$ while employing $0.025 \mathrm{mg} / \mathrm{Kg}$ body weight and $218 \mathrm{~s}$ while no priming dose was used. ${ }^{17}$

Veena et al. compared the onset of Cisatracurium for tracheal intubation with and without priming dose of rocuronium. Patients were divided into two groups of 30 each. Patients in Group $\mathrm{R}$ received priming dose of rocuronium $0.06 \mathrm{mg} / \mathrm{Kg}$ before intubating dose of Cisatracurium $(0.14 \mathrm{mg} / \mathrm{Kg})$. Group C patients did not get any priming, only normal saline was given before intubating dose of Cisatracurium $(0.15 \mathrm{mg} / \mathrm{Kg})$. Time gap between administration of the Cisatracurium and complete loss of TOF count 1 was recorded as intubation time which was significantly less in Group R (130 \pm 11.02 s) compared to Group C $(230.33 \pm 12.82$ s). Priming with rocuronium decreased the onset time without increasing the clinical duration of action or recovery index. ${ }^{18}$

Rao MS et al. in his study evaluated the intubating conditions and time required for rapid, smooth tracheal intubation using the "principle of priming" with NDMR Vecuronium bromide. Group I consisted of 20 patients who received a bolus dose of $0.1 \mathrm{mg} / \mathrm{Kg}$ Vecuronium, the mean intubating time was 149 seconds in $70 \%$ of cases. In Group II, 20 patients received a priming dose of $0.015 \mathrm{mg} / \mathrm{Kg}$, intubating dose of $0.6 \mathrm{mg} / \mathrm{Kg}$ with 5 minutes interval. Adequate intubating conditions were achieved in 96 seconds in $80 \%$ of cases. In Group III20 patients received a priming dose of $0.02 \mathrm{mg} / \mathrm{Kg}$ and intubating dose of $0.08 \mathrm{mg} / \mathrm{Kg}$. Adequate intubating conditions were achieved in 63 seconds in all patients. ${ }^{19}$

So, it can be seen that our observations are consistent with observations of Schmidt J et al., Duggappa et al., Veena et al. and Rao MS et al. That priming significantly reduces the onset time of NDMR and also this reduction is higher with higher priming doses.

In group-A, 26(86.7\%) patients had excellent intubation scores and $4(13.33 \%)$ patients had good intubation scores. In group-B, 29(96.7\%) patients had excellent intubation score and $1(3.3 \%)$ patients had good intubation score. In group-C, all $30(100 \%)$ patients had excellent intubation scores. There was no patient of fair and poor intubation score in all three groups. There was no statistically significant difference in intubation score among different groups $(\mathrm{p}=0.0637)$. So the present study showed that priming did not alter the intubating condition. 
In their study Rao MS et al. found that intubating conditions were clinically acceptable in all three groups where two different priming doses were used in two groups and no priming was used in a group. ${ }^{19}$ Study done by Sindhu K. Sridhar et al. showed that intubating conditions were clinically acceptable in all three groups. Intubating conditions were compared by the Cooper scoring system. In the study by Veena et al., in Group R, 28 (93.3\%) of 30 patients had excellent intubating conditions and two (6.67) patients had good intubating conditions. In Group C 27 (90\%) patients had excellent intubating conditions and three $(10 \%)$ patients had good intubating conditions. The difference between the two groups was statistically insignificant $(\mathrm{P}>0.05)$. So, these studies (Sindhu K. Sridhar et. al., Veena et. al., Rao MS et. al) are consistent with the finding of our study regarding priming dose and intubating conditions.

We found that different priming dose does not affect haemodynamic parameters, $\mathrm{EtCO}_{2}$ and $\mathrm{SpO}_{2}$ and this corroborates with observation of Veena et al. None of the patients in all groups suffered any adverse effects of priming such as diplopia, ptosis during priming interval. Dugappa et al. did not found any clinically significant adverse effect with priming dose of Atracurium.

\section{CONCLUSIONS}

Priming dose of Cisatracurium reduces the onset time for intubation without affecting intubating conditions, haemodynamic parameters, $\mathrm{EtCO}_{2}, \mathrm{SpO}_{2}$ and does not cause adverse effects. The reduction in the onset time for intubation is more with higher $(15 \%)$ priming doses than with lower $(10 \%)$ priming doses.

\section{REFERENCES}

[1] Gergis SD, Sokoll MD, Mehta $M$, et al. Intubation conditions after atracurium and suxamethonium. $\mathrm{Br}$ J Anaesth 1983;Suppl 55:83S-6S.

[2] Doherty WG, Breen PJ, Donati F, et al. Accelerated onset of pancuronium with divided doses. Can Anaesth Soc J 1985;32(1):1-4.

[3] Schwarz S, Ilias W, Lachner F, et al. Rapid trachel intubation with vecuronium: the priming principle. Anesthesiology 1985;62(4):388-91.

[4] Mehta MP, Choi WW, Gergis SD, et al. Facilitation of rapid endotracheal intubations with divided doses of nondepolarizing neuromuscular blocking drugs. Anaesthesiology 1985;62(4):392-5.

[5] Taboada JA, Rupp SM, Miller RD. Refining the priming principle for vecuronium during rapid-sequence induction of anaesthesia. Anaesthesiology 1986;64(2):243-7.

[6] Baumgarten RK, Carter CE, Reynolds WJ, et al. Priming with non-depolarizing relaxants for rapid tracheal intubation: a double-blind evaluation. Canadian Journal of Anaesthesia 1988;35(1):5-11.

[7] Naguib M, Gyasi HK, Abdulatif M, et al. Rapid tracheal intubation with atracurium - a comparison of priming intervals. Can Anaesth Soc J 1986;33(2):150-6.

[8] Naguib M, Abdullatif M, Absood GH. The optimal priming dose for atracurium. Can Anaesth Soc J 1986;33(4):4537.

[9] Bruce DL, Downs JB, Kulkarni PS, et al. Precurization inhibits maximal venilatory efforts. Anaesthesiology 1984;61(5):618-21.

[10] Sridhar SK, Lagoo JY, Sathyanarayana PS. A comparative study to evaluate the effects of priming on intubating time and conditions with rocuronium bromide. Karnataka Anaesth J 2015;1(2):55-9.

[11] Hutton P, Morgan G, El-Hassan K, et al. Speeding the onset of neuromuscular block by alcuronium. $\mathrm{Br} \mathrm{J}$ Anaesth 1983;55:918.

[12] Foldes F. Rapid tracheal intubation with nondepolarizing neuromuscular blocking drugs: the priming principle. Br J Anaesth 1984;56(6):663.

[13] Naguib M, Lien CA. Pharmacology of muscle relaxants and their antagonists. In: Miller RD, edr. Miller's Anaesthesia. $7^{\text {th }}$ edn. Philadelphia: Churchill Livingstone 2010: p. 859-911.

[14] Engbaek J, Howardy-Hansen P, Ording H, et al. Precurarization with vecuronium and pancuronium in awake, healthy volunteers: the influence on neuromuscular transmission and pulmonary function. Acta Anaesthesiology Scand 1985;29(1):117-20.

[15] Baldini G. Neuromuscular blocking agents. In: Butterworth JF, Mackey DC, Wasnick JD, eds. Morgan \& Mikhail's Clinical Anaesthesiology. $6^{\text {th }}$ edn. India: McGraw-Hill 2018: p. 199-222.

[16] Schmidt J, Albrecht S, Petterich $N$, et al. Priming technique with cisatracurium Onset time at the laryngeal muscles. Anaesthesist 2007;56(10):992-1000.

[17] Duggappa AKH, Mathew S, Kordcal AR, et al. Prospective comparative randomized controlled study to determine the optimal priming dose of atracurium. Ind J Respir Care 2018;7(1):42-5.

[18] Veena C, Harpreet K, Reena M, et al. Compare Onset time of cisatracurium for tracheal intubation with and without priming dose of rocuronium. Int J Sci Stud 2019;6(11):102-6.

[19] Rao MS, Prasad TVVSV, Kumudha. Priming principle and rapid sequence intubation with non-depolarising muscle relaxant vecuronium bromide. J Evolution Med Dent Sci 2018;7(11):1308-12. 